\title{
Cancer immunotherapy: Role of the immune system in malignant transformation
}

\author{
Rodrigo R. Sandoval-Valencia* \\ Servicio de Cirugía Pediátrica, Hospital Pediátrico Baca Ortiz, Quito, Ecuador
}

\begin{abstract}
The immune system is the body's primary defense mechanism and functions by recognizing specific antigens through receptors in the cell membrane. Immunoediting is based on the theory that cancer cells are influenced by the immunological environment in which they develop and consists of three phases: recognition, equilibrium, and elimination. Moreover, chronic inflammation contributes to malignant transformation by acting as a promoter of genetic mutations that provide neoplastic cells with the ability to proliferate uncontrollably, while allowing them to develop mechanisms to evade recognition by immune cells. Immunotherapy emerges as a promising type of treatment against neoplasms that fail to respond to conventional treatment in an adequate manner while offering the possibility of reducing the adverse effects associated with conventional treatments.
\end{abstract}

Key words: Immunosurveillance. Cancer immunoediting. Immunotherapy. Tumor antigen. Adoptive immunotherapy.

\section{Introduction}

The immune system is the body's primary defense mechanism and functions by recognizing specific antigens through receptors in the cell membrane.

Once the antigen has bound to its receptor, an intracellular signal is emitted with the consequent activation of transcription factors entrusted with activating specific genes, which will trigger certain immune responses with the aim of guaranteeing the integrity of the human being.

In accordance with this principle, the concept of "immunosurveillance" arose in the early $19^{\text {th }}$ century, which argues that the immunological system can recognize and eliminate the growth of carcinogenic cells $s^{1,2}$. To consolidate this idea, studies were conducted on knockout mice deficient in interferons (IFN)- $\gamma$ or perforin, molecules that are crucial for the development of an adequate immune response. Methylcolantrene, a carcinogenic chemical substance, was injected, illustrating that genetically modified mice developed higher percentages of tumors in comparison with control mice ${ }^{3-5}$.

Moreover, the role of specific immunity in controlling tumor growth is illustrated in that the recombination activating genes (RAG) are affected. It has been proven that the lack of the RAG-2 enzyme, one of the molecules involved in $\mathrm{V}(\mathrm{D}) \mathrm{J}$ somatic recombination in developing lymphocyte receptors, increases the percentage of sarcomas in the affected mice when compared with control mice ${ }^{6,7}$.

Furthermore, the role of the immune system in human beings is made clear in studies involving transplanted patients who have undergone immunosuppressive therapy due to their condition ${ }^{8,9}$

These patients register a greater tendency to develop specific neoplasms in comparison with the general
Correspondence:

*Rodrigo R. Sandoval-Valencia

E-mail: ricardorsv44@gmail.com
Available online: 17-10-2019 Rev Med Hosp Gen Mex. 2019;82(4):198-207 www.hospitalgeneral.mx under the CC BY-NC-ND license (http://creativecommons.org/licenses/by-nc-nd/4.0/). 
population, including lymphoproliferative disorders, renal carcinomas, and hepatobiliary carcinomas, among others $^{9,10}$. Moreover, we describe a greater risk of developing neoplasms with established viral etiology such as Kaposi sarcomas, cervix carcinomas, and anal-rectal carcinomas ${ }^{11}$; however, it cannot be guaranteed that this propensity is due to the patient's own predisposition or to a less effective immunosurveillance process arising from the immunosuppressive therapy administered.

Likewise, a number of studies demonstrate that the infiltration of immune cells in neoplastic tissue biopsies is associated with a better prognosis of life in patients suffering from different types of tumor, establishing the relationship between the immune system and cancer cells ${ }^{12-14}$.

\section{Immunoediting: the birth of a new concept}

Although the immunosurveillance mechanism and the importance of the immune system in the growth of cancer cells have been established, the development of neoplasms in immunocompetent persons has not been fully explained. Dunn et al. argue that cancer cells are influenced by the immune environment in which they develop and that the elimination of high immunogenicity tumor cells enables tumor variants with reduced immunogenicity to keep on developing, either due to the fact the immune system is unable to recognize them or due to the fact they have developed mechanisms that enable them to evade the immune system ${ }^{15}$.

Due to the fact that, in accordance with this argument the immune system would be involved not only in protecting the organism against cancer cells but would also play a major role in its growth and subsequent development, the use of the term "immunoediting" was proposed, which underlines the dual role of the immune system with regard to neoplastic cells ${ }^{14}$. As such, the immunoediting process comprises three phases: elimination, equilibrium, and escapement ${ }^{15,16}$ (Fig. 1).

\section{Elimination phase}

This phase represents the original concept of immunosurveillance, in which the innate and adaptive immune systems work together to stem the growth of neoplastic cells and destroy them before they become clinically evident ${ }^{17}$.

It is not known for sure which mechanisms enable the immune system to detect tumor cells, but it is believed that cytokines play a significant role, including type-I
IFN; molecular patterns associated with the damage released by the cells themselves, the most noteworthy of which are hyaluronan and high mobility group protein 1; and stress-associated ligands expressed on the surface of neoplastic cells (MIC-A/B), which would be recognized by specific receptors in natural killer (NK) cells ${ }^{18}$.

If this phase is conducted successfully and the tumor is eradicated, the immunoediting process would be complete without the need to conduct the subsequent phases.

\section{Equilibrium phase}

This phase is an intermediate status of the immune response to cancer cells. It is probably the longest phase in the process and might last throughout their life in some individuals ${ }^{18}$

In this phase the immune system coexists with the tumor cells in a state of inactivity; however, it is possible that latent neoplastic cells could reactive their growth capacity as recurrent tumors or as distant metastasis ${ }^{19}$.

The cell inactivity and angiogenic inactivity mechanisms complement the function of the adaptive immune system of keeping tumor cells in an equilibrium phase. In the former scenario, the cancer cells enter a state of quiescence awaiting the right time to start growing again while angiogenic inactivity prevents the tumor from expanding due to the absence of vascularization ${ }^{20,21}$.

Once the tumor cells have found an appropriate environment, they will undergo a series of genetic changes, thereby increasing their resistance to the immune system and giving rise to the next phase of the process ${ }^{22}$.

\section{Escape phase}

This phase represents a fault in the immune system in relation to eliminating or controlling neoplastic cells, thereby enabling these cells to continue to grow with no suitable control.

We have addressed two possibilities by means of which tumor cells are able to evade the immune system: intrinsic mechanisms associated with tumor antigens and extrinsic mechanisms associated with the immune system of the individual in question (Fig. 1) ${ }^{23}$.

Several forms of escapement have been described in the former category, the most noteworthy of which are the loss of type-I major histocompatibility complex (MHC) molecules on the surface of cancer cells ${ }^{24}$ and the lack of response through the receptors for type-I (IFN- $\alpha$ and IFN- $\beta$ ) and type-II (IFN- $\gamma$ ) IFN ${ }^{25}$, which prevents the elimination of neoplastic cells through the action of T cluster of differentiation (CD8) lymphocytes. 


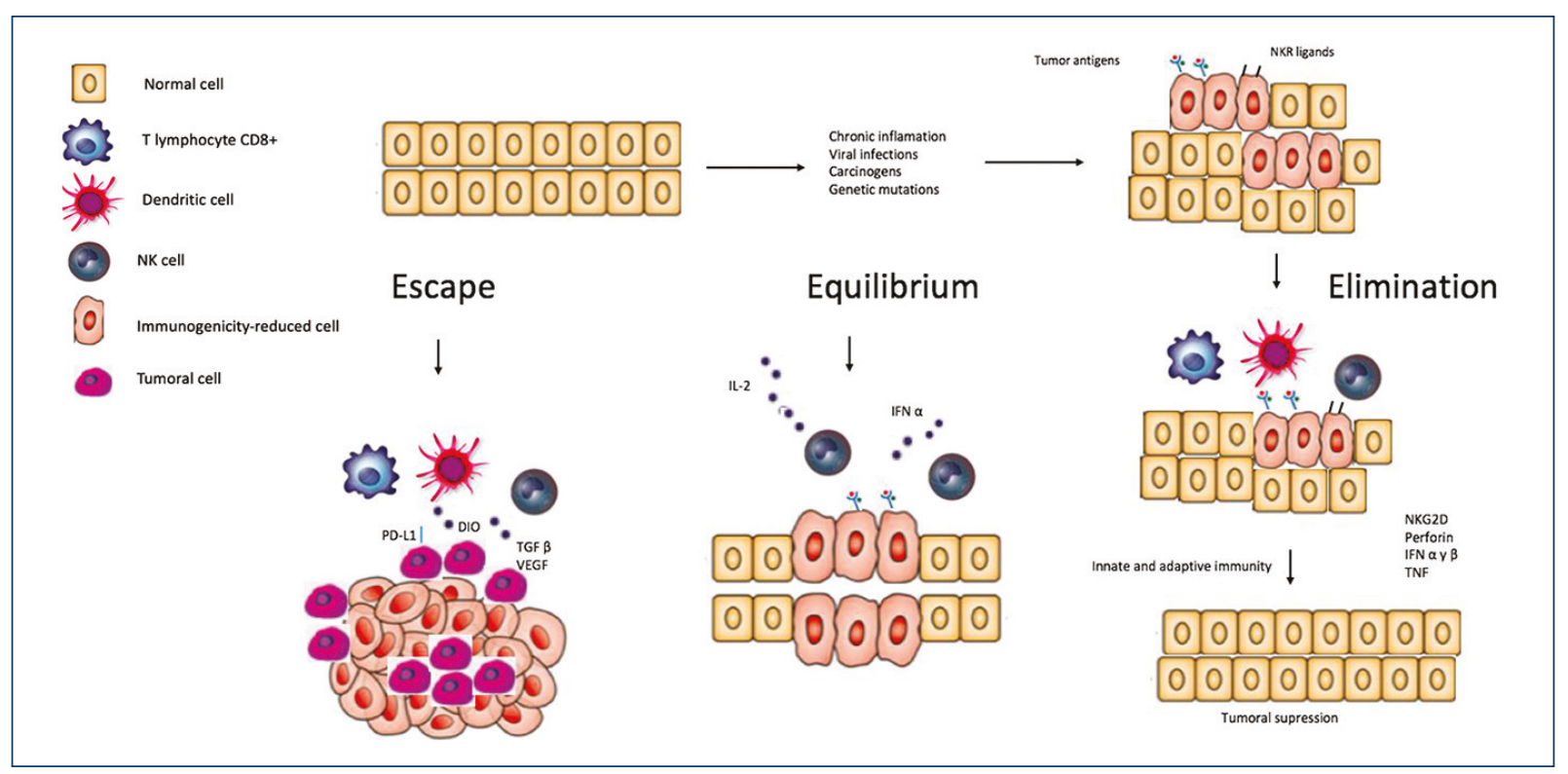

Figure 1. The immunoediting process (adapted from: Finn OJ. A believer's overview of cancer immunosurveillance and immunotherapy. J. Immunol. 2018 and Lussier DM, Schreiber RD. Cancer Immunosurveillance: Immunoediting. Ref Mod Biomed Sciences. 2016).

Moreover, some tumors may reduce the expression of molecules associated with the processing of antigens within the cell, affecting the transporter associated with the processing of antigens (TAP1) and tapasin glycoprotein ${ }^{26}$.

Furthermore, some neoplastic cells constitutively express the indoleamine 2,3-dioxygenase (DIO) enzyme entrusted with degrading the amino acid tryptophan, thereby generating a powerful resistance to the immune system due to a lack of proliferation of T CD8 lymphocytes in the tumor bed ${ }^{27}$.

Moreover, the increase in the L-arginine metabolic pathway in tumors related to myeloid cells and the consequent overproduction of nitric oxide could inhibit the T-lymphocyte cytolytic function ${ }^{28}$.

Dendritic cells can also be affected by the tumor microenvironment, with a reduction in their antigen-presenting capacity, and losing it completely in some cases, thus rendering them incapable of starting a proper connection with the specific immunity ${ }^{29}$.

The growth factors and the cytokines produced by neoplastic cells promote the growth of the same while helping develop a suitable tumor microenvironment.

Vascular endothelial growth factor is a crucial sign for tumor angiogenesis, in addition to being involved in inhibiting the maturation of dendritic cell maturation ${ }^{30}$. Moreover, the excessive production of transforming growth factor-beta is associated with a reduction in immune capacity due to the inhibition of the activation of dendritic cells, T cells, and NK cells ${ }^{31}$.
For a link to exists between the innate and specific immune system, the antigen-presenting cell function must be intact, as well as the costimulation signals partly from the B7-1 and B7-2 proteins with their CD28 receptor. It is acknowledged that several different types of cancer cells can inhibit these costimulation signals, thereby protecting them from being recognized and eliminated by cytotoxic T-lymphocytes ${ }^{32}$.

In spite of extensive research, the exact mechanisms through which cancer cells are able to evade the immune system are not known for sure; however, it is believed that the combination of the tumor microenvironment and the molecules and factors generated by neoplastic cells affects the development, maturation, and subsequent differentiation of immune cells ${ }^{33,34}$.

Table 1 provides a summary of the potential escapement mechanisms through which cancer cells evade the immune system.

\section{The role of inflammation in the tumor microenvironment}

Inflammation is one of the organism's biological responses to a tissue lesion with the aim of maintaining adequate homeostasis. Once the damage has been done, a series of interrelated processes are set in motion, the most noteworthy of which are the activation and migration of leukocytes, the vasodilation and activation of the vascular endothelium, and the production 
of inflammatory mediators. It should be pointed out that the inflammation process is strictly controlled with the aim of preventing permanent activation and a possible deleterious response.

In the mid-18 $8^{\text {th }}$ century, Virchow suggested an association between chronic inflammation and the carcinogenesis process on observing leukocyte infiltrates in neoplastic tissue ${ }^{35}$. Subsequent research substantiated this association by linking the inflammatory microenvironment produced during the development of neoplastic cells with the constitutive activation of certain transcription factors, capable of inhibiting the apoptosis mechanism and stimulating cell proliferation ${ }^{36}$.

According to Mantovani et al., the existing connection between chronic inflammation and the carcinogenesis process can be explained in two routes: an extrinsic route in which the inflammatory conditions in certain types of disease increase the possibility of developing neoplasms (a greater risk of gastric cancer and MALT in chronic infections due to Helicobacter pylori, and a greater risk of colorectal cancer in patients with inflammatory bowel disease ${ }^{37}$ ), and an intrinsic route mediated by oncogenes capable of producing pro-inflammatory cytokines and chemokines with the consequent creation of an inflammatory tumor microenvironment ${ }^{38}$.

It has been proven that chronic inflammation contributes to the process in the three phases of development. The initiation of the tumor processes refers to the point at which neoplastic cells acquire a mutation that renders them capable of proliferating and greater advantage of survival when compared with normal cells. The inflammatory tumor microenvironment increases mutation rates due to the excessive production of reactive oxygen species and reactive nitrogen intermediates, which are capable of causing damage to the DNA with consequent genomic instability ${ }^{39}$.

The promotion phase consists of the growth of the tumor from a cell that acquired previous mutations in the initiation phase. The tumor microenvironment contributes to this phase by increasing the rate of cell proliferation, improving survival, and reducing the rate of cell death ${ }^{39,40}$.

Finally, the progression phase is favored by the recruitment of tumor-associated macrophages, specific cells capable of detecting hypoxia signals, with the consequent production of pro-angiogenic cytokines and the development of new crucial blood vessels to ensure the growth of the tumor, invasion, and, in some cases, metastasis ${ }^{39,41}$.

Table 1. Evasion of the immune system by cancer cells

\section{Mechanisms}

Dependent antigens

Reduction in $\mathrm{MCH}$ I molecules

Insensitivity of IFN receptors

Changes in antigen processing

Tumor microenvironment

Tryptophan degradation (DIO)

Overproduction of nitric oxide

Alteration of dendritic cells

Inhibition of costimulatory signals

Excessive production of VEGF and TGF- $\beta$

Preparation: own sources.

MHC: major histocompatibility complex molecules; IFN: interferons;

DIO: indoleamine 2,3-dioxigenase enzyme; VEFG: vascular endothelial growth factor; TGF- $\beta$ : transforming growth factor-beta.

Table 2. Special characteristics of tumor cells

\section{Special characteristics of tumor cells}

Growth signal self-sufficiency

Ability to evade apoptosis

Insensitivity to antigrowth signals

Unlimited replicative potential

Sustained angiogenesis

Tissue invasion and metastasis

\section{Distinctive characteristics of the carcinogenesis process}

The carcinogenesis process involves a series of molecular changes in the cell growth and proliferation regulatory circuits, consisting of genetic alterations resulting in the transformation of normal cells into malignant cells.

Due to the diversity of existing neoplasms and mechanisms involved in the cell transformation process, in early 2000 Hanahan and Weinberg suggested that a large amount of tumor genotypes is a manifestation of six essential alterations in cell physiology that together contribute to neoplastic transformation ${ }^{42}$ (Table 2).

In spite of the major impact this work caused, it did not take into account the role of the immune system or the tumor microenvironment, reason for which it was proposed that neoplastic cells in growth, besides complying with the characteristics listed by Hanahan and Weinberg, are likely to survive in an inflammatory microenvironment, while evading and suppressing immunological recognition and reactivity ${ }^{43}$. 


\section{Immunotherapy: a new treatment option}

Immunotherapy has arisen as an innovative therapeutic option that can be used in certain types of neoplasms, in addition to pan drug-resistant bacterial infections, which are currently a global problem. A comprehensive understanding of the mechanisms involved in bacterial resistance and neoplastic cell transformation processes is fundamental in this type of treatment.

The origin of immunotherapy dates back to the late $18^{\text {th }}$ century, when Coley reported that the tumor regressed when inoculating patients with neoplasms with cultures of live bacteria. This hypothesis was based on the production of an immune reaction against a toxin from the bacterial culture that generated a cross-response capable of destroying the tumor cells ${ }^{44}$; however, we now know that the immune response produced was due to the recognition mediated by toll-type receptors (TLR) ${ }^{45}$.

A preparation derived from Streptococcus pyogenes, OK-432, has been shown to act through the complex TLR4/MD2, thereby stimulating the maturation of dendritic cells and the production of Th-1 cytokines in patients with neoplasms of the head and neck ${ }^{46,47}$; moreover, on using it together with chemotherapy in patients with Stages III and IV gastric cancer after undergoing a curative resection, the preparation was shown to slightly increase the average survival rate ${ }^{48}$.

In recent years, the combination of types of therapy has been effective in treating certain types of neoplasms of the lymphatic system. Sclerotherapy using OK-342 has proven to be effective in the treatment of cystic lymphangiomas ${ }^{49}$, and registering satisfactory long-term results ${ }^{50}$, and, moreover, a new rating based on the findings in relation to the endothelial architecture of lymphatic malformations has been proposed according to the study conducted by Malic et al. ${ }^{51}$

It is also known that the bacillus Calmette-Guerin (BCG) is capable of stimulating cytotoxic T lymphocytes (CTL), NK cells and macrophages ${ }^{52,53}$, and, as such, have been widely used in the prevention of recurrences of non-muscle invasive bladder cancer ${ }^{54}$, as well as prophylaxis in patients with bladder cancer undergoing a transurethral resection ${ }^{55}$.

It has been established that the BCG mechanism action occurs through the activation of the immune system and the induction of an inflammatory state. Once the installation has been conducted, the urothelial cancer cells, by means of a macropinocytosis process, internalize the bacillus, which causes MHC II molecule expression and the production of interleukins by the tumor cells, and a consequent recruitment of lymphocytes in the tumor microenvironment, the same ones that secrete Th- 1 cytokines with the consequent activation of CD8 T-lymphocytes, NK cells and granulocytes entrusted with destroying the tumor cells ${ }^{56}$.

Despite the positive results obtained in relation to this type of treatment, frequent adverse events have been registered, the most significant of which are cystitis, hematuria, and fever; however, potentially severe cases such bladder urothelium necrosis ${ }^{57}$, hepatitis, pneumonitis, and even miliary tuberculosis have been documented ${ }^{58}$.

Furthermore, certain polysaccharides such as polysaccharide $K$ (PSK) have proven to be beneficial in long-term survival acting as a non-specific immunopotentiator when combined with conventional chemotherapy in patients with gastric cancer undergoing surgical resection ${ }^{59}$, and in patients with cancer of the colon undergoing curative resection ${ }^{60,61}$.

Despite the fact that the exact mechanism of action of PSK has not been fully explained, it is currently believed to have a mitogenic effect on the NK cell line, the production of interleukin 2, and an increase in the expression of receptors for interleukin 2 in the cell membrane of lymphocytes. Due to the insidious presentation of gastrointestinal neoplasms, the rapid development and high degree of malignancy, early diagnosis is difficult, and, as such, patients developing symptoms often have advanced stages of the disease. According to the study conducted by Ma et al., the use of polysaccharide has a beneficial effect on overall survival and disease-free survival without increasing secondary effects ${ }^{62}$.

Moreover, cytokines have demonstrated a beneficial effect when used as a adjuvant therapy, such as the case of INF- $\alpha$, which is capable of inducing the expression of type-1 $\mathrm{MCH}$ molecules, in addition to participating in the maturation of dendritic cells and the activation of CTL, NK cells, and macrophages ${ }^{63}$. Its use as adjuvant therapy in high-risk cutaneous melanoma demonstrates a significant benefit in disease-free survival, as well as long-term survival ${ }^{64,65}$. According to current studies, combined therapy using INF- $\alpha$ significantly reduces the risk of relapse and improves survival without showing any difference in relation to the dose used ${ }^{66}$.

In addition, the benefit of the use of INF- $\alpha$ in B-cell lymphoma and multiple myeloma is illustrated in the study conducted by Zhang et al.; there is a need to conduct future research to establish the impact of IFN- $\alpha$ on this type of neoplasms, as well as to 
determine the dose and the ideal therapeutic regimen for the use of the same ${ }^{67}$.

Metastatic melanoma and renal carcinoma do not respond to chemotherapy in a satisfactory manner, the reason for which new types of treatment using high doses of IL-2 has been taken into consideration, obtaining positive results in relation to the disease control rate ${ }^{68}$. Likewise, Hughes et al. registered a favorable association on using high doses of interleukin 2 in patients with stable disease with an increase in survival ${ }^{69}$.

Another type of treatment consists of the use of genetically modified T-cells; a variety of these cells is produced on fusing the antigen-binding region of an antibody with the $\mathrm{CD} 3 \zeta$ cell transduction domains present in T-cell receptors (TCRs) and costimulatory molecules such as CD28 and 4-1BB, resulting in a T-cell with a chimeric antigen receptor $(\mathrm{CAR})^{70}$. A remission of $90 \%$ was reported on using this type of treatment in patients with acute lymphoblastic leukemia relapses ${ }^{71}$.

Furthermore, on using a variety of CAR T cells directed toward the CD19 antigen present in neoplastic cells and $B$ cells, promising results were obtained on treating patients with diffuse large B-cell lymphoma refractory to chemotherapy treatment ${ }^{72,73}$.

This type of immunotherapy has been widely accepted due to the advantages it possesses. One of these advantages is the capacity to choose the receptor properties to be used and the cell population to be handled. Moreover, genetic modification allows for the use of genes through vectors with the aim of coding certain molecules involved in the prevention of apoptosis, induction of inflammation and cell costimulation with the aim of achieving a satisfactory anti-tumor immune response ${ }^{74}$.

Due to the mechanism of action of CAR T-cells, the positive results obtained in hematological neoplasms and the fact that many neoplastic cells close to their surrounding stroma have developed mechanisms to evade being recognized and eliminated by T-cells, further research is required using this type of treatment. Gomes-Silva and Ramos recommend the use of CAR T-cells in solid tumors with certain genetic modifications that would result in: an increase in the production of cytokines to modulate the tumor microenvironment, the creation of CAR T-cells resistant to inhibitor signals, in addition to the use of combined treatments for immunological synapse ${ }^{75}$.

Furthermore, the existing disadvantages are due to the fact that the receptors have a monoclonal specificity, meaning a small area of attack on the tumor, thereby facilitating the development of antigenic variants that could evade immune recognition. Furthermore, treatment with CAR T-cells could produce adverse effects due to a cross-reaction in structures that mimic the specific antigen ${ }^{75}$, or through the excessive production of cytokines once the genetically created receptor has bonded with its respective antigen ${ }^{76}$.

At the same time, the development of new molecular biology techniques has seen the identification of a number of different antigens arising from specific mutations in tumor cells, reason for which, on identifying these peptides in the MHC molecules expressed in the cell membrane, the specific cytotoxic T-lymphocytes for this antigen can be stimulated with the aim of obtaining an effective immune response against the tumor cell ${ }^{77}$.

Moreover, one of the challenges this type of treatment poses is the use of a viral vector entrusted with transducing the information from the chimeric receptor to the T-cells. This vector is required to relay quality controls in relation to safety, sterility, concentration, and purity due to the fact it will be administered directly in the patient. Due to the fact that the vectors used are oncogenic, there is a possibility of insertional mutagenesis at the time of vector DNA integration in the host cells. According to Zhang et al., it is important to develop a standardized manufacturing process to allow for the comparison of results obtained for the different types of neoplasms ${ }^{78}$.

It has been documented that the infiltration of lymphocytes in neoplastic tissue biopsies is associated with a better prognosis of life, reason for which attempts were made at isolating tumor-infiltrating lymphocytes (TIL), with the aim of stimulating them in vitro to obtain reactive T-cells against specific tumor antigens ${ }^{79}$.

A study was conducted in patients with metastatic melanoma consisting of the infusion of TIL together with IL-2; beforehand, they underwent an ablative myeloma preparative regimen using chemotherapy on its own or combined with radiotherapy. A clinically objective response was obtained using RECIST criteria from $49 \%$ to $72 \%$; however, $22 \%$ of the patients registered a complete remission, showing that this type of therapy can be beneficial regardless of the previous treatment used $^{80}$.

Pursuant to current evidence, it has proven possible to propose a predictive value and prognosis for TIL in relation to different types of solid neoplasms, reason for which the creation of a standardized methodology allowing for an increase in the evidence available on the use of these lymphocytes is recommended, while allowing for the creation and implementation of a 
Table 3. Types of immunotherapy used in cancer

\begin{tabular}{|c|c|c|}
\hline Therapy used & Neoplasm & References \\
\hline OK-432 & $\begin{array}{l}\text { Neoplasms of the head and neck } \\
\text { Gastric cancer }\end{array}$ & $46-51,89$ \\
\hline Calmette-Guerin Bacillus & Bladder cancer & $52-58,89$ \\
\hline Polysaccharide K & $\begin{array}{l}\text { Gastric cancer } \\
\text { Cancer of the colon }\end{array}$ & $59-62,89$ \\
\hline INF- $\alpha$ & Melanoma & $63-67,89$ \\
\hline IL-2 & Renal carcinoma & $68,69,89$ \\
\hline CAR T-cells & $\begin{array}{l}\text { Acute lymphoblastic leukemia } \\
\text { Large B-cell diffuse lymphoma }\end{array}$ & $71-73,75,89$ \\
\hline TIL & Melanoma & $80,81,89$ \\
\hline Ipilimumab & Melanoma & $85-89$ \\
\hline Nivolumab & Melanoma & 89,90 \\
\hline
\end{tabular}

Source: own. OK-432: preparation derived from Streptococcus pyogenes;

INF- $\alpha$ : interferon alpha; IL-2: interleukin 2; CAR T-cells: T-cells with chimeric antigen receptor; TIL: tumor infiltrating lymphocytes; Ipilimumab: monoclonal antibody targeting CTLA-4; Nivolumab: monoclonal antibody targeting PD-1.

score-based prognosis scale that can be used in routine histopathological practice and at the time of conducting clinical studies ${ }^{81}$.

Moreover, it is known that two crucial signals are required for the satisfactory activation of T-lymphocytes: one is mediated by the TCR and the specific antigen recognition, while the second occurs through stimulatory or inhibitory signals as the case may be, in what is known as immunological synapse ${ }^{82}$.

It has been demonstrated that an inhibitory molecule, the cytotoxic T-lymphocyte associated antigen 4 (CTLA-4), also bonds to B7, but with a greater affinity than CD28; this union produces a downward regulation of the cell response mediated by T-lymphocytes, producing energy in the cell in some cases ${ }^{83}$.

On blocking the interaction between CTLA-4 and B7 using a monoclonal antibody: ipilimumab, a proliferation, and activation of T-lymphocytes is produced due to the inhibitory modulation being blocked, which is thought to result in a reduction in tumor growth ${ }^{84}$.

Positive results were registered using ipilimumab combined with the gp100 peptide vaccine in patients with Stages III and IV unresectable melanoma, obtaining a statistically significant average survival rate when compared with the group that did not use the antibody. In spite of the results obtained, adverse effects were reported, predominantly in relation to cutaneous and gastrointestinal issues ${ }^{85}$.

Furthermore, ipilimumab was used in combination with dacarbazine in patients with previously untreated metastatic melanoma, obtaining a significant average survival rate in the patients that underwent the combined therapy, in comparison with those subjected to monotherapy or dacarbazine plus placebo. As in the previous study, adverse effects were registered; however, due to the possibility of dealing with them in a satisfactory manner, treatment with CTLA-4 inhibitors is a promising and widely-accepted therapy ${ }^{86}$.

As a result of the positive results obtained, Corneliu et al. conducted a study to assess the efficacy and safety of treatment with ipilimumab in patients with advanced unresectable melanoma and metastatic melanoma. This study showed that the average survival rate was related to the number of doses administered ${ }^{87}$.

Furthermore, a comparison was conducted on the use of ipilimumab combined with radiotherapy versus ipilimumab on its own in patients with metastatic melanoma, registering a statistically significant difference in the average survival rate in the group that used the combined treatment ${ }^{88}$.

Another glycoprotein expressed on the surface of effector cells is the programmed cell death coreceptor molecule 1 (PD-1), which plays a major role in the modulation and activation of the immune system. However, when expressed in tumor cells, it becomes involved in the escapement process, as well as the evasion of recognition and elimination by immune effector cells ${ }^{89}$.

Phase III studies have been completed using nivolumab, a monoclonal antibody directed toward the PD-1 molecule, in solid tumors such as renal cell 
carcinoma, melanoma, and lung cancer, obtaining encouraging results. Based on these studies, Tie et al. demonstrated that the use of nivolumab resulted in a better response to treatment when compared to traditional chemotherapy, and that, despite the fact the use of an antibody is not exempt from adverse effects, such effects are less significant than those caused by chemotherapy ${ }^{90}$.

Significant progress has been made in recent years with regard to the development and implementation of immunotherapy as a therapeutic regime in neoplasms that fail to adequately respond to conventional treatment. In spite of the results obtained, prospective studies need to be conducted to demonstrate the true benefits of the different types of immunotherapy. A summary of the different types of immunotherapy is provided in table 3.

\section{Conclusions}

The transformation of normal cells into cancer cells is a multi-systemic process in which the affectation of the circuits that control the cell cycle due to genetic mutations, the inflammatory tumor microenvironment and the signals emitted from the surrounding stroma, provide tumor cells with special characteristics and the capacity to grow uncontrollably.

The role of the immune system as a defense mechanism is crucial to maintaining adequate homeostasis. This is due to the capacity to recognize molecules foreign to the organism and to distinguish between pathogenic elements that might threaten the integrity of the host, in addition to foreign antigens produced by mutations within the malignant transformation process present in the cell surface of antigen-presenting cells.

Immunoediting highlights the relationship between the immune system and cancer cells. Once the underlying molecular mechanisms have been established, immunotherapy arises as a therapeutic option for patients who have undergone traditional therapy that was ineffective in controlling and detaining tumor growth.

The new types of treatment to appear in recent years have produced encouraging results; however, prospective studies need to be conducted with which to consolidate and illustrate the true impact of immunotherapy.

Moreover, the possibility exists of using immunotherapy as an option for bacterial infections due to the capacity of receptors to recognize antigens in the bacterial cell membrane. In accordance with the results obtained, this type of treatment has a good chance of success.

\section{Conflicts of interest}

The author declares that they have no conflicts of interest.

\section{Ethical disclosures}

Protection of human and animal subjects. The authors declare that no experiments were performed on humans or animals for this study.

Confidentiality of data. The authors declare that no patient data appear in this article.

Right to privacy and informed consent. The authors declare that no patient data appear in this article.

\section{References}

1. Burnet M. Cancer: a biological approach. III. Viruses associated with neoplastic conditions. IV. Practical applications. Br Med J. 1957;1:841-7.

2. Burnet FM. The concept of immunological surveillance. Prog Exp Tumor Res. 1970;13:1-27.

3. Kaplan DH, Shankaran V, Dighe AS, Stockert E, Aguet M, Old LJ, et al. Demonstration of an interferon gamma-dependent tumor surveillance system in immunocompetent mice. Proc Natl Acad Sci U S A. 1998;95:7556-61.

4. van den Broek ME, Kägi D, Ossendorp F, Toes R, Vamvakas S, Lutz WK et al. Decreased tumor surveillance in perforin-deficient mice. J Exp Med. 1996;184:1781-90.

5. Street SE, Cretney E, Smyth MJ. Perforin and interferon-gamma activities independently control tumor initiation, growth, and metastasis. Blood. 2001;97:192-7.

6. Shankaran V, Ikeda H, Bruce AT, White JM, Swanson PE, Old LJ, et al. IFNgamma and lymphocytes prevent primary tumour development and shape tumour immunogenicity. Nature. 2001:410:1107-11.

7. Shinkai Y, Rathbun G, Lam KP, Oltz EM, Stewart V, Mendelsohn M, et al. RAG-2-deficient mice lack mature lymphocytes owing to inability to initiate V(D)J rearrangement. Cell. 1992;68:855-67.

8. Sheil AG. Cancer after transplantation. World J Surg. 1986;10:389-96

9. Penn I. Post-transplant malignancy: the role of immunosuppression. Drug Saf. 2000;23:101-13.

10. Penn I. Tumors of the immunocompromised patient. Annu Rev Med 1988;39:63-73.

11. Dunn GP, Bruce AT, Ikeda H, Old LJ, Schreiber RD. Cancer immunoediting: from immunosurveillance to tumor escape. Nat Immunol. 2002;3:991-8.

12. Clemente CG, Minm MC Jr., Bufalino R, Zurrida S, Collini P, Cascinelli N, et al. Prognostic value of tumor infiltrating lymphocytes in the vertical growth phase of primary cutaneous melanoma. Cancer. 1996;77:1303-10.

13. Naito $Y$, Saito $K$, Shiiba K, Ohuchi A, Saigenji K, Nagura H, et al. CD8+T cells infiltrated within cancer cell nests as a prognostic factor in human colorectal cancer. Cancer Res. 1998;58:3491-4.

14. Ishigami S, Natsugoe S, Tokuda K, Nakajo A, Che X, Iwashige $H$, et al. Prognostic value of intratumoral natural killer cells in gastric carcinoma. Cancer. 2000;88:577-83.

15. Dunn GP, Old LJ, Schreiber RD. The three es of cancer immunoediting. Annu Rev Immunol. 2004;22:329-60.

16. Dunn GP, Old LJ, Schreiber RD. The immunobiology of cancer immunosurveillance and immunoediting. Immunity. 2004:21:137-48.

17. Chow MT, Möller A, Smyth MJ. Inflammation and immune surveillance in cancer. Semin Cancer Biol. 2012;22:23-32.

18. Schreiber RD, Old LJ, Smyth MJ. Cancer immunoediting: integrating immunity's roles in cancer suppression and promotion. Science. 2011:331:1565-70.

19. Aguirre-Ghiso JA. Models, mechanisms and clinical evidence for cancer dormancy. Nat Rev Cancer. 2007;7:834-46.

20. Koebel CM, Vermi W, Swann JB, Zerafa N, Rodig SJ, Old LJ, et al. Adaptive immunity maintains occult cancer in an equilibrium state. Nature. 2007;450:903-7.

21. Teng MW, Swann JB, Koebel CM, Schreiber RD, Smyth MJ. Immune-mediated dormancy: an equilibrium with cancer. J Leukoc Biol. 2008:84:988-93.

22. Bhatia A, Kumar Y. Cancer Immunoediting: immunosurveillance, Immune Equilibrium, and Immune Escape. En: cancer Immunology: a Translational Medicine. Berlin, Heidelberg: Springer; 2015. p. 195-208.

23. Smyth MJ, Dunn GP, Schreiber RD. Cancer immunosurveillance and immunoediting: the roles of immunity in suppressing tumor development and shaping tumor immunogenicity. Adv Immunol. 2006;90:1-50. 
24. Algarra I, Cabrera T, Garrido F. The HLA crossroad in tumor immunology. Hum Immunol. 2000;61:65-73.

25. Dunn GP, Koebel CM, Schreiber RD. Interferons, immunity and cancer immunoediting. Nat Rev Immunol. 2006:6:836-48.

26. Atkins D, Breuckmann A, Schmahl GE, Binner P, Ferrone S, Krummenauer F et al. MHC class I antigen processing pathway defects, ras mutations and disease stage in colorectal carcinoma. Int J Cancer. 2004;109:265-73.

27. Uyttenhove C, Pilotte L, Théate I, Stroobant V, Colau D, Parmentier N, et al. Evidence for a tumoral immune resistance mechanism based on tryptophan degradation by indoleamine 2,3-dioxygenase. Nat Med. 2003;9:1269-74.

28. Bronte V, Zanovello P. Regulation of immune responses by L-arginine metabolism. Nat Rev Immunol. 2005;5:641-54.

29. Ma Y, Shurin GV, Peiyuan Z, Shurin MR. Dendritic cells in the cancer microenvironment. J Cancer. 2013;4:36-44.

30. Gabrilovich DI, Ishida T, Nadaf S, Ohm JE, Carbone DP. Antibodies to vascular endothelial growth factor enhance the efficacy of cancer immunotherapy by improving endogenous dendritic cell function. Clin Cancer Res. 1999;5:2963-70.

31. Wrzesinski SH, Wan YY, Flavell RA. Transforming growth factor-beta and the immune response: implications for anticancer therapy. Clin Cancer Res. 2007;13:5262-70.

32. Zang X, Allison JP. The B7 family and cancer therapy: costimulation and coinhibition. Clin Cancer Res. 2007;13:5271-9.

33. Zou W. Immunosuppressive networks in the tumour environment and their therapeutic relevance. Nat Rev Cancer. 2005;5:263-74.

34. Zitvogel L, Tesniere A, Kroemer G. Cancer despite immunosurveillance: immunoselection and immunosubversion. Nat Rev Immunol. 2006 6:715-27.

35. Balkwill $F$, Mantovani $A$. Inflammation and cancer: back to virchow? Lancet. 2001;357:539-45.

36. Karin M. Nuclear factor-kappaB in cancer development and progression Nature. 2006;441:431-6

37. Waldner MJ, Neurath MF. Colitis-associated cancer: the role of T cells in tumor development. Semin Immunopathol. 2009;31:249-56.

38. Mantovani A, Allavena P, Sica A, Balkwill F. Cancer-related inflammation. Nature. 2008;454:436-44.

39. Grivennikov SI, Greten FR, Karin M. Immunity, inflammation, and cancer Cell. 2010;140:883-99.

40. Coussens LM, Werb Z. Inflammation and cancer. Nature. 2002;420:860-7

41. Condeelis J, Pollard JW. Macrophages: obligate partners for tumor cell migration, invasion, and metastasis. Cell. 2006;124:263-6.

42. Hanahan D, Weinberg RA. The hallmarks of cancer. Cell. 2000;100:57-70.

43. Cavallo F, De Giovanni C, Nanni P, Forni G, Lollini PL. 2011: the immune hallmarks of cancer. Cancer Immunol Immunother. 2011;60:319-26.

44. Zacharski LR, Sukhatme VP. Coley's toxin revisited: immunotherapy or plasminogen activator therapy of cancer? J Thromb Haemost. 2005; 3:424-7.

45. Kumar $\mathrm{H}$, Kawai T, Akira S. Pathogen recognition in the innate immune response. Biochem J. 2009:420:1-6.

46. Okamoto M, Oshikawa T, Tano T, Ohe G, Furuichi S, Nishikawa H, et al Involvement of toll-like receptor 4 signaling in interferon-gamma production and antitumor effect by streptococcal agent OK-432. J Natl Cance Inst. 2003:95:316-26.

47. Okamoto M, Furuichi S, Nishioka Y, Oshikawa T, Tano T, Ahmed SU, et al. Expression of toll-like receptor 4 on dendritic cells is significant for anticancer effect of dendritic cell-based immunotherapy in combination with an active component of OK-432, a streptococcal preparation. Cancer Res. 2004;64:5461-70.

48. Oba MS, Teramukai S, Ohashi Y, Ogawa K, Maehara Y, Sakamoto J, et al. The efficacy of adjuvant immunochemotherapy with OK-432 after curative resection of gastric cancer: an individual patient data meta-analysis of randomized controlled trials. Gastric Cancer. 2016;19:616-24.

49. Mitsukawa N, Satoh K. New treatment for cystic lymphangiomas of the face and neck: cyst wall rupture and cyst aspiration combined with sclerotherapy. J Craniofac Surg. 2012;23:1117-9.

50. Weitz-Tuoretmaa A, Rautio R, Valkila J, Keski-Säntti H, Keski-Nisula L, Laranne J, et al. Efficacy of OK-432 sclerotherapy in treatment of lymphatic malformations: long-term follow-up results. Eur Arch Otorhinolaryngol. 2014;271:385-90

51. Malic CC, Guilfoyle R, Courtemanche RJ, Arneja JS, Heran MK, Courtemanche DJ, et al. Lymphatic malformation architecture: implications for treatment with OK-432. J Craniofac Surg. 2017;28:1721-4.

52. Böhle A, Brandau S. Immune mechanisms in bacillus calmette-guerin immunotherapy for superficial bladder cancer. J Urol. 2003;170:964-9.

53. Haaff EO, Catalona WJ, Ratliff TL. Detection of interleukin 2 in the urine of patients with superficial bladder tumors after treatment with intravesical BCG. J Urol. 1986;136:970-4

54. Gandhi NM, Morales A, Lamm DL. Bacillus calmette-guérin immunotherapy for genitourinary cancer. BJU Int. 2013;112:288-97.

55. Librenjak D, Situm M, Eterovic D, Dogas Z, Gotovac J. Immunoprophylactic intravesical application of bacillus calmette-guerin after transurethra resection of superficial bladder cancer. Croat Med J. 2003;44:187-92.
56. Redelman-Sidi G, Glickman MS, Bochner BH. The mechanism of action of BCG therapy for bladder cancer a current perspective. Nat Rev Urol. 2014;11:153-62.

57. Krönig $M$, Jilg $C$, Burger D, Langer $M$, Timme-Bronsert S, Werner $M$ et al. BCG induced necrosis of the entire bladder urothelium. Urol Case Rep. 2015;3:161-3.

58. Batista M, Alves C, Boinas C, Camacho E. Tuberculosis miliary in patients treated with bacillus calmette-guerin immunotherapy: case report J Med Cases. 2017;8:233-5.

59. Oba K, Teramukai S, Kobayashi M, Matsui T, Kodera Y, Sakamoto J, et al. Efficacy of adjuvant immunochemotherapy with polysaccharide $\mathrm{K}$ for patients with curative resections of gastric cancer. Cancer Immuno Immunother. 2007;56:905-11

60. Ito K, Nakazato H, Koike A, Takagi H, Saji S, Baba S, et al. Long-term effect of 5-fluorouracil enhanced by intermittent administration of polysaccharide $\mathrm{K}$ after curative resection of colon cancer. A randomized controlled trial for 7-year follow-up. Int J Colorectal Dis. 2004;19:157-64.

61. Sakamoto J, Morita S, Oba K, Matsui T, Kobayashi M, Nakazato H, et al. Efficacy of adjuvant immunochemotherapy with polysaccharide $\mathrm{K}$ fo patients with curatively resected colorectal cancer: a meta-analysis of centrally randomized controlled clinical trials. Cancer Immunol Immunother. 2006;55:404-11.

62. Ma Y, Wu X, Yu J, Zhu J, Pen X, Meng X, et al. Can polysaccharide $K$ improve therapeutic efficacy and safety in gastrointestinal cancer? A systematic review and network meta-analysis. Oncotarget. 2017;8: 89108-18.

63. Lee S, Margolin K. Cytokines in cancer immunotherapy. Cancers (Basel). 2011;3:3856-93

64. Mocellin S, Pasquali S, Rossi CR, Nitti D. Interferon alpha adjuvant therapy in patients with high-risk melanoma: a systematic review and meta-analysis. J Natl Cancer Inst. 2010:102:493-501.

65. Mocellin S, Lens MB, Pasquali S, Pilati P, Chiarion Sileni V. Interferon alpha for the adjuvant treatment of cutaneous melanoma. Cochrane Database Syst Rev. 2013;6:CD008955.

66. Ives NJ, Suciu S, Eggermont AM, Kirkwood J, Lorigan P, Markovic SN et al. Adjuvant interferon- $\alpha$ for the treatment of high-risk melanoma: an individual patient data meta-analysis. Eur J Cancer. 2017;82:171-83.

67. Zhang L, Tai YT, Ho MZ, Qiu L, Anderson KC. Interferon-alpha-based immunotherapies in the treatment of B cell-derived hematologic neoplasms in today's treat-to-target era. Exp Hematol Oncol. 2017;6:20.

68. Alva A, Daniels GA, Wong MK, Kaufman HL, Morse MA, McDermott DF et al. Contemporary experience with high-dose interleukin-2 therapy and impact on survival in patients with metastatic melanoma and metastatic renal cell carcinoma. Cancer Immunol Immunother. 2016;65:1533-44.

69. Hughes T, Klairmont M, Broucek J, lodice G, Basu S, Kaufman HL, et al. The prognostic significance of stable disease following high-dose interleukin-2 (IL-2) treatment in patients with metastatic melanoma and renal cell carcinoma. Cancer Immunol Immunother. 2015;64:459-65.

70. Gill S, June $\mathrm{CH}$. Going viral: chimeric antigen receptor T-cell therapy for hematological malignancies. Immunol Rev. 2015;263:68-89.

71. Maude SL, Frey N, Shaw PA, Aplenc R, Barrett DM, Bunin NJ, et al Chimeric antigen receptor $T$ cells for sustained remissions in leukemia N Engl J Med. 2014;371:1507-17.

72. Kochenderfer JN, Dudley ME, Carpenter RO, Kassim SH, Rose JJ, Telford WG, et al. Donor-derived CD19-targeted T cells cause regression of malignancy persisting after allogeneic hematopoietic stem cell transplantation. Blood. 2013;122:4129-39.

73. Kochenderfer JN, Dudley ME, Kassim SH, Somerville RP, Carpenter RO Stetler-Stevenson M, et al. Chemotherapy-refractory diffuse large B-cel lymphoma and indolent B-cell malignancies can be effectively treated with autologous $T$ cells expressing an anti-CD19 chimeric antigen receptor. J Clin Oncol. 2015;33:540-9.

74. Restifo NP, Dudley ME, Rosenberg SA. Adoptive immunotherapy for cancer: harnessing the T cell response. Nat Rev Immunol. 2012;12:269-81.

75. Gomes-Silva D, Ramos CA. Cancer immunotherapy using CAR-T cells: from the research bench to the assembly line. Biotechnol J. 2018; 13:1700097

76. Morgan RA, Yang JC, Kitano M, Dudley ME, Laurencot CM, Rosenberg SA, et al. Case report of a serious adverse event following the administration of $T$ cells transduced with a chimeric antigen receptor recognizing ERBB2. Mol Ther. 2010;18:843-51.

77. Schumacher TN, Schreiber RD. Neoantigens in cancer immunotherapy Science. 2015;348:69-74

78. Zhang C, Liu J, Zhong JF, Zhang X. Engineering CAR-T cells. Biomark Res. 2017;5:22

79. Rosenberg SA, Restifo NP. Adoptive cell transfer as personalized immunotherapy for human cancer. Science. 2015;348:62-8

80. Rosenberg SA, Yang JC, Sherry RM, Kammula US, Hughes MS Phan GQ, et al. Durable complete responses in heavily pretreated patients with metastatic melanoma using T-cell transfer immunotherapy. Clin Cancer Res. 2011:17:4550-7.

81. Hendry S, Salgado R, Gevaert T, Russell PA, John T, Thapa B, et al. Assessing tumor-infiltrating lymphocytes in solid tumors: a practical re- 
view for pathologists and proposal for a standardized method from the international immuno-oncology biomarkers working group: Part 2: tils in melanoma, gastrointestinal tract carcinomas, non-small cell lung carcinoma and mesothelioma, endometrial and ovarian carcinomas, squamous cell carcinoma of the head and neck, genitourinary carcinomas, and primary brain tumors. Adv Anat Pathol. 2017;24:311-35.

82. Huppa JB, Davis MM. T-cell-antigen recognition and the immunological synapse. Nat Rev Immunol. 2003;3:973-83.

83. Perez VL, Van Parijs L, Biuckians A, Zheng XX, Strom TB, Abbas AK et al. Induction of peripheral $T$ cell tolerance in vivo requires CTLA-4 engagement. Immunity. 1997;6:411-7.

84. Korman AJ, Peggs KS, Allison JP. Checkpoint blockade in cancer immunotherapy. Adv Immunol. 2006;90:297-339.

85. Hodi FS, O'Day SJ, McDermott DF, Weber RW, Sosman JA, Haanen JB et al. Improved survival with ipilimumab in patients with metastatic melanoma. N Engl J Med. 2010;363:711-23.
86. Robert C, Thomas L, Bondarenko I, O'Day S, Weber J, Garbe C, et al Ipilimumab plus dacarbazine for previously untreated metastatic melanoma. N Engl J Med. 2011;364:2517-26

87. Corneliu Jinga D, Ciuleanu T, Negru S, Aldea C, Gales L, Bacanu F, et al. Effectiveness and safety profile of ipilimumab therapy in previously treated patients with unresectable or metastatic melanoma the romanian patient access program. J BUON. 2017;22:1287-95

88. Koller KM, Mackley HB, Liu J, Wagner H, Talamo G, Schell TD, et al Improved survival and complete response rates in patients with advanced melanoma treated with concurrent ipilimumab and radiotherapy versus ipilimumab alone. Cancer Biol Ther. 2017;18:36-42.

89. Yamaguchi, Y. Immunotherapy of Cancer: an Innovative Treatment Comes of Age. Japan: Springer; 2016. p. 283-94.

90. Tie Y, Ma X, Zhu C, Mao Y, Shen K, Wei X, et al. Safety and efficacy of nivolumab in the treatment of cancers: a meta-analysis of 27 prospective clinical trials. Int J Cancer. 2017;140:948-58. 